\title{
Effect of Foliar Application of Phosphorus on Rhizosphere and Rhizoplane Fungal diversity in Brassica juncea
}

\author{
Walay Y. Tagade ${ }^{1 *}$, M. V. Kawale ${ }^{2}$, R. B. Zode ${ }^{3}$ and R. P. Thakre ${ }^{4}$ \\ ${ }^{1,3}$ Department of Botany, C.J. Patel College, Tirora, Dist- Gondia, Maharashtra-441911 \\ ${ }^{2}$ Department of Botany, Dhote Bandhu Science College, Gondia, Maharashtra-441614 \\ ${ }^{4}$ Department of Botany, RTM Nagpur University, Nagpur, Maharashtra- 440033 \\ Corresponding authorEmail: walaytagade@gmail.com \\ (Submitted on July 2, 2020; Accepted on November 9, 2020)
}

\begin{abstract}
The microbial communities, also called as microhabitat, play an important role in the growth and development of the plants. The rhizosphere fungal diversity is always different from the non-rhizosphere fungal diversity. The foliar application of fertilizers has significant effect on fungal diversity of rhizosphere. Hence, a study was conducted to understand the effect of foliar application of phosphorus on the rhizosphere and rhizoplane fungal diversity of cultivar line EH-3 and varuna variety of Brassica juncea. The foliar application of potassium dihydrogen phosphate as a source of phosphorus was used at the concentration of 0.5 and $1 \%$. The foliar application of phosphorus resulted in considerable changes in the fungal diversity of treated plants as compared to the control plants. During the study in all 36 fungal species were isolated from rhizosphere and non-rhizosphere soil. The number of fungal colonies were found to be more during the flowering stage as compared to seedling and maturity stage. Aspergillus sp. was found to be significantly dominant compared to other rhizosphere fungal diversity as it was documented to account for $30-40 \%$ rhizosphere fungal microbes followed by Fusarium sp. which was around $15 \%$. Apart from these, remaining all fungi documented were found to account for less than $10 \%$ of the fungal population. The rhizoplane study also revealed that the per cent occurrence of Aspergillus sp. was more in control as well as in treated plants of EH-3 and variety varuna.
\end{abstract}

KEYWORDS: EH-3, Foliar application, phosphorus, rhizoplane, rhizosphere, fungal diversity.

\section{INTRODUCTION}

The rhizosphere is an ecological niche of the soil, adjacent to root system of plants. It provides the microhabitat for the aerobic and anaerobic microorganism. Interactions between soil microorganisms and plant roots satisfy important nutrient requirements for both plant and associated microorganisms. Similarly, rhizoplane is an immediate external surface of plant roots together with closely adhering soil particles or root debris. The striking influence that root exert on the rhizosphere is the stimulation for various types of microorganisms such as algae, bacteria and fungi and this effect is known as rhizosphere effect. It generally depends on the release of organic substances by plant roots which stimulate the growth of microorganisms (Liljeroth and Baath, 1988).

Addition of plant nutrients in soil or foliar application of nutrients on plant causes variation in the exudation of some chemicals by the plant roots. The altered root exudation also changes the pattern of rhizosphere microflora both on qualitative and quantitative basis (Raaijmakers et.al., 2009). The application of micronutrients $(\mathrm{Cu}, \mathrm{Fe}, \mathrm{Mn}$ and $\mathrm{Zn})$ at the rate of $500 \mathrm{mg} /$ liter has been reported to significantly increase wheat straw yield and grain quality (Seadh et.al., 2009). Phosphorus is one of the important macronutrients for the growth and development of plants (Hameeda et.al., 2008). It plays an important role in many biological processes. However, the strong adsorption of phosphorus by minerals in the soil is reported to decrease its availability to plants, therefore reducing the productivity of agricultural and forest ecosystems (Kafle et.al., 2019). Hence, the foliar application of potassium dihydrogen phosphate $\left(\mathrm{KH}_{2} \mathrm{PO}_{4}\right)$ in the form of phosphorus is normally given to alter the rhizosphere fungal diversity.

Dhedhi et. al., (1990) studied the rhizosphere and rhizoplane of wilted and root-rot diseased plant of Chickpea and suggested that the diseased and healthy plants show considerable variation in rhizosphere and rhizoplane fungal diversity. Jha and Jalali (2006) documented and evaluated the biocontrol potential of the fungal isolates from Pea (Pisum sativum) rhizosphere against Fusarium solani f. sp. pisi. Likewise there are many studies on soil microbes and fungi of non-rhizosphere, rhizosphere and rhizoplane but there is little study on the fungal diversity of rhizosphere and rhizoplane of Brassica juncea. In view of this the present study has been undertaken on variety varuna (containing high amount of glucosinolate and susceptible to white rust) and selection line EH-3 (Early Heera, containing very low amount of glucosinolate and resistant to white rust) of Brassica juncea.

\section{MATERIALS AND METHODS}

Description of the study area: To investigate the rhizosphere and rhizoplane fungal diversity of Brassica juncea, variety varuna and cultivar line EH-3 was selected to conduct the experiments. The seeds for this purpose were procured from the Dhara Vegetable Oil and Foods Company Ltd. (DOFCO) sponsored project, Department of Botany, R.T.M. Nagpur University, Nagpur, Maharashtra, India. The seeds were grown in the field and foliar applications were done so as to alter the rhizosphere and rhizoplane fungal diversity (Fig. 1).

Potassium dihydrogen phosphate treatment: Foliar application of the 0.5 and $1 \%$ phosphorus was given by using potassium dihydrogen phosphate purified $\left(\mathrm{KH}_{2} \mathrm{PO}_{4}\right)$ at three different stages, i.e. seedling, flowering and maturity stage.

Collection of rhizosphere soil samples: Three soil samples were collected during the different stages of plant growth (i.e. seedling, flowering and maturity) from the experimental field of Post Graduate Teaching Department of Botany; RTM Nagpur University Campus Nagpur, Maharashtra, India. Roots of healthy plants with adhering soil and NRS (nonrhizosphere soil) were collected and transferred to the sterile plastic bags and brought to the laboratory for examination.

Isolation of Fungi: Rhizospheric fungal microorganisms 


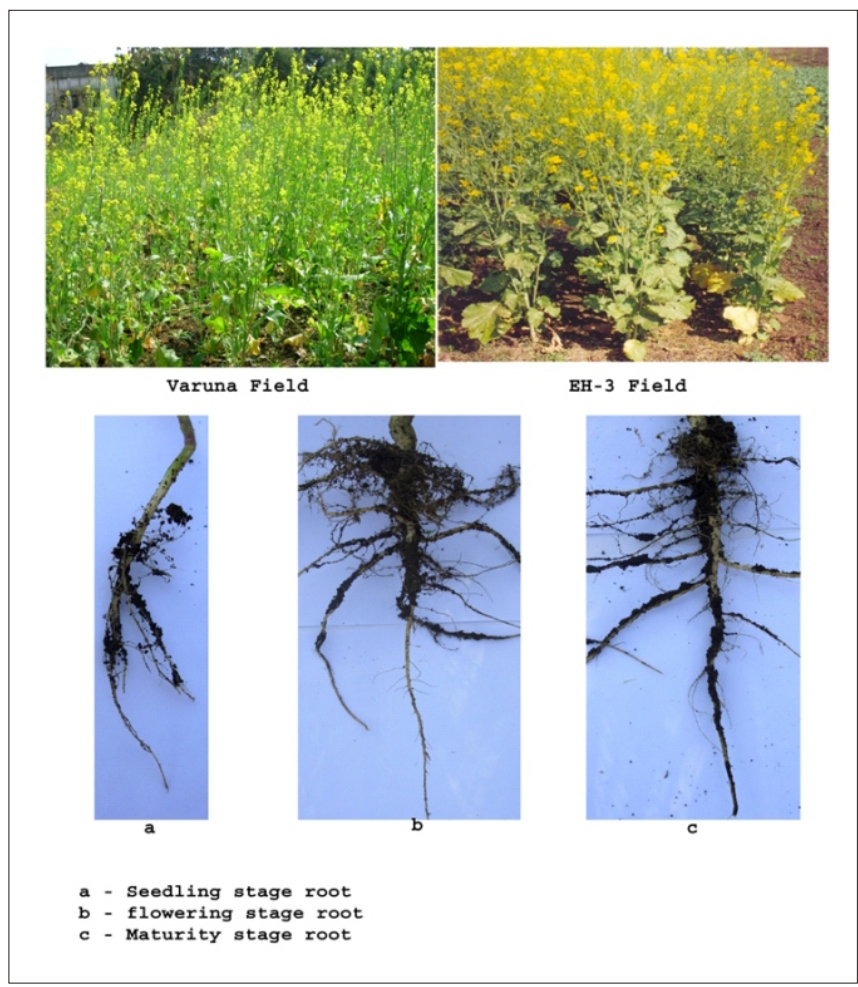

Fig.1. Experimental field and roots with rhizosphere oil.

were isolated by serial dilution plate technique (Johnson and Curl, 1972) using Czepak's Dox agar medium. After incubation, the number of colonies which appeared on plates, were counted and per cent occurrence of particular fungus was calculated. Likewise, the rhizosphere effect was studied employing the method given by Katznelson (1946). A numerical value and the R:S ratio was used to compare the fungal microorganisms present in the rhizosphere with the fungal population present outside of the rhizosphere soil.

1. Isolation of rhizoplane fungi: The rhizoplane fungi were isolated by serial-root washings technique (Harley and Waid, 1955).

2. Identification of fungi: The fungi isolated from rhizosphere and rhizoplane were identified by consulting standard literature (Nagmani et.al., 2006, Booth, 1977; Raper and Fennell, 1965; Raper and Thom, 1949).

\section{RESULTS}

Rhizosphere fungi: The foliar application of phosphorus resulted in considerable changes in fungal diversity documented in the rhizosphere of cultivar EH-3 and variety varuna as compared to the control plants. During the investigation, total 36 fungal species were isolated from NRS and rhizosphere of control and treated plants of cultivar EH-3 and variety varuna. The different fungi isolated were Absidia sp., Alternaria alternata, Alternaria sp., Aspergillus clavatus A. fischeri A. flavipes, $A$. flavus, A. fumigatus, $A$. nidulans, $A$. niger, A. ochraceus, A. sulphureus, A. sydowii, A. terreus, A. wentii, Chaetomium globosum, Cladosporium sp., Curvularia lunata, Curvularia sp., Drechslera sp., Fusarium graminearum, F. oxysporum, Fusarium sp., Helminthosporium sp., Penicillium citrinum, $P$. purpurogenum, $P$. lilacinum, $P$. oxalicum, P. multicolor, Penicillium sp. 1, Penicillium sp. 2, Phoma sp., Rhizopus stolonifer, Syncephalastrum sp., Trichoderma viride isolate I and II.

In all 22 fungal species were obtained from the nonrhizosphere soil (NRS). These are Absidia sp., Alternaria alternata, Alternaria sp., Aspergillus flavus, A. fumigatus, A. niger, A. ochraceus, A. sulphureus, A. sydowii, A. terreus, $A$. wentii, Cladosporium sp., Curvularia lunata, Fusarium graminearum, $F$. oxysporum, Penicillium citrinum, $P$. lilacinum, P. multicolor, $P$. oxalicum, Penicillium sp., Rhizopus stolonifer and Syncephalastrum sp. Likewise, in all 27 and 28 species of fungi were isolated from rhizosphere of control plants of cultivar EH-3 and variety varuna, respectively. Amongst the 27 species isolated from the rhizosphere of cultivar EH-3; Aspergillus clavatus, Chaetomium globosum, Fusarium sp., Helminthosporium sp., Penicillium sp. 2 and Phoma sp. were not observed in NRS. Apart from these fungi, Aspergillus wentii, Fusarium graminearum, Penicillium sp. 1 and Syncephalastrum sp. were isolated from NRS but not from control plants of cultivar EH-3. Similarly, out of 28 fungi isolated from variety varuna rhizosphere; Aspergillus fischeri, A. flavipes, A. nidulans, Chaetomium globosum, Curvularia sp., Drechslera sp., Fusarium sp. Helminthosporium sp., and Penicillium purpurogenum were not observed in non-rhizosphere soil. However, fungal species like Aspergillus sydowii, A. terreus, $A$. wentii and Penicillium sp. 1 were isolated from NRS but not observed in the rhizosphere of variety varuna.

The foliar application of phosphorus was found to significantly alter the rhizospheric fungal diversity. The total fungi isolated from 0.5 and $1 \%$ P treated cultivar EH-3 plants were 27 and 24, respectively. Specially Fusarium graminearum, Penicillium purpurogenum, Trichoderma viride isolate I and II were observed in $0.5 \% \mathrm{P}$ treated plants of cultivar EH-3 while, Aspergillus ochraceous, A. sydowii, Cladosporium sp., Penicillium sp. 2 were not documented but were found to be present in control. Similarly, Fusarium graminearum, Syncephalastrum sp. and Trichoderma viride isolate II were isolated from the $1 \% \mathrm{P}$ treated plants of cultivar EH-3 while Aspergillus sydowii, Fusarium sp. were not documented but were present in control.

In variety varuna, in all 29 and 30 fungal species were documented in the rhizosphere of 0.5 and $1 \% \mathrm{P}$ treated plants, respectively. Aspergillus clavatus, A. sydowii, A. terreus, A. wentii, Penicillium sp. 2, Trichoderma viride isolate I and II were isolated from $0.5 \% \mathrm{P}$ treated plants however, fungi like Asprgillus fischeri, A. sulphureus, Cladosporium sp., Penicillium purpurogenum and Syncephalastrum sp. were found to be absent but these were present in the rhizosphere of control plants. Similarly, in 1\% P treated plants of variety varuna, fungi like Aspergillus sydowii, A. terreus, A. wentii, Trichoderma viride isolate I and II were observed whereas, fungi like Cladosporium sp., Penicillium oxalicum and Syncephalastrum sp. were altogether absent but these were isolated from the rhizosphere of control plants. On overall basis fungi like Aspergillus sp. and Penicillium sp. were 
found to dominate throughout the study. Total 12 Aspergillus species were isolated from the rhizosphere and nonrhizosphere soil. Aspergillus flavus, A. fumigatus and A. niger were constantly isolated from the rhizosphere soil and NRS. Similarly 7 Penicillium sp. were obtained from rhizosphere soil and NRS. Penicillium citrinum was the most constant species obtained throughout (Table 1).

Table 1: Incidence of Fungi in NRS and rhizosphere of treated plants of cultivar EH-3 and variety varuna

\begin{tabular}{|c|c|c|c|c|c|c|c|c|}
\hline \multirow{2}{*}{$\begin{array}{l}\text { Sr. } \\
\text { No. }\end{array}$} & \multirow[t]{2}{*}{ Fungal species } & \multirow[t]{2}{*}{ NRS } & \multicolumn{3}{|c|}{ Cultivar EH-3 } & \multicolumn{3}{|c|}{ Variety varuna } \\
\hline & & & $\mathbf{C}$ & $0.5 \% \mathrm{P}$ & $1 \% \mathrm{P}$ & $\mathbf{C}$ & $0.5 \% \mathrm{P}$ & $1 \% \mathrm{P}$ \\
\hline 1. & Absidia sp. & + & + & + & + & + & + & + \\
\hline 2. & Alternaria alternata & + & + & + & + & + & + & + \\
\hline 3. & Alternaria sp. & + & + & + & + & + & + & + \\
\hline 4. & Aspergillus clavatus & - & + & + & + & - & + & - \\
\hline 5. & Aspergillus fischeri & - & - & - & - & + & - & + \\
\hline 6. & Aspergillus flavipes & - & - & - & - & + & + & + \\
\hline 7. & Aspergillus flavus & + & + & + & + & + & + & + \\
\hline 8. & Aspergillus fumigatus & + & + & + & + & + & + & + \\
\hline 9. & Aspergillus nidulans & - & + & + & - & + & + & + \\
\hline 10. & Aspergillus niger & + & + & + & + & + & + & + \\
\hline 11. & Aspergillus ochraceus & + & + & - & + & + & + & + \\
\hline 12. & Aspergillus sulphureus & + & + & + & + & + & - & + \\
\hline 13. & Aspergillus sydowii & + & + & - & - & - & + & + \\
\hline 14. & Aspergillus terreus & + & + & + & + & - & + & + \\
\hline 15. & Aspergillus wentii & + & - & - & - & - & + & + \\
\hline 16. & Cladosporium sp. & + & + & - & + & + & - & - \\
\hline 17. & Chaetomium globosum & - & + & + & + & + & + & + \\
\hline 18. & Curvularia lunata & + & + & + & + & + & + & + \\
\hline 19. & Curvularia sp. & - & + & + & + & + & + & + \\
\hline 20. & Drechslera sp. & - & + & + & + & + & + & + \\
\hline 21. & Fusarium graminearum & + & - & + & + & + & + & + \\
\hline 22. & Fusarium oxysporum & + & + & + & + & + & + & + \\
\hline 23. & Fusarium sp. & - & + & + & - & + & + & + \\
\hline 24. & Helminthosporium sp. & - & + & + & + & + & + & + \\
\hline 25. & Penicillium citrinum & + & + & + & + & + & + & + \\
\hline 26. & Penicillium liliacinum & + & + & + & - & + & + & + \\
\hline 27. & Penicillium multicolor & + & + & - & - & + & - & + \\
\hline 28. & Penicillium oxalicum & + & + & + & + & + & + & - \\
\hline 29. & P. purpurogenum & - & - & + & - & + & - & + \\
\hline 30. & Penicillium sp. 1 & + & - & - & - & - & - & - \\
\hline 31. & Penicillium sp. 2 & - & + & - & - & - & + & - \\
\hline 32. & Phoma sp. & - & + & + & + & + & + & + \\
\hline 33. & Rhizopus stolonifer & + & + & + & + & + & + & + \\
\hline 34. & Syncephalastrum $\mathrm{sp}$. & + & - & + & + & + & - & - \\
\hline 35. & Trichoderma viride isolate I & - & - & + & - & - & + & + \\
\hline 36. & Trichoderma viride isolate II & - & - & + & + & - & + & + \\
\hline
\end{tabular}

The 36 fungal taxa isolated from rhizosphere and NRS were found to be belonging to 14 fungal genera. Aspergillus sp., were most abundant both in the rhizosphere and nonrhizosphere soil and represented $30-40 \%$ of the documented fungi followed by Fusarium sp. which were around 15\%. Apart from these, fungi like Alternaria sp., Curvularia sp., Penicillium sp., were almost around $10 \%$ while all other species were around 5\% in both the treatments of EH-3 and variety varuna. Drechslera sp., Chaetomium globosum, Phoma sp., and Helminthosporium sp. were not isolated from non-rhizosphere soil but isolated from the rhizosphere soil of control plants of cultivar EH-3 and variety varuna. However, Trichoderma sp. were not isolated from both the control plants as well as NRS but it was present in P sprayed plants. Moreover, the per cent occurrence of most of the fungi was more in the soil sprayed with $0.5 \% \mathrm{P}$ in comparison to those sprayed with $1 \% \mathrm{P}($ Fig. 3 and 4$)$.

The rhizosphere study revealed that the maximum number of colonies were there during the flowering stage in comparison to a maturity and seedling stage in control as well as treated plants. It also revealed that maximum fungal

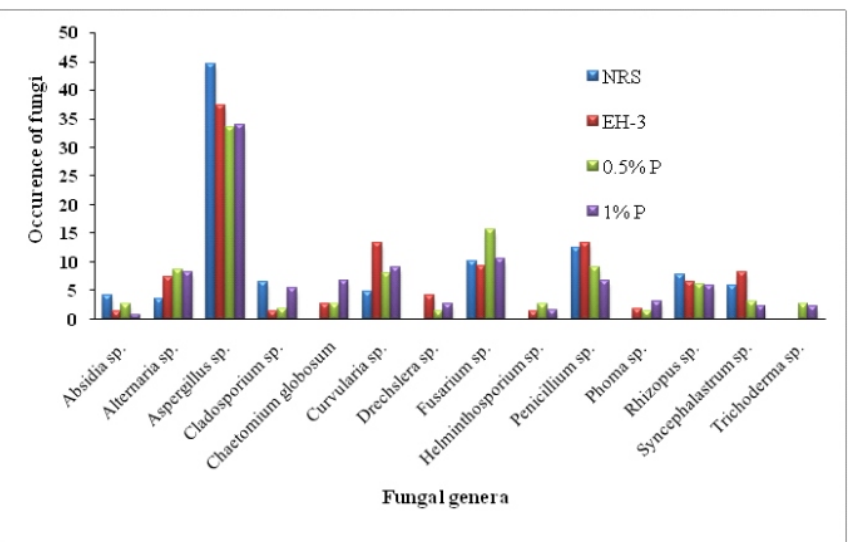

Fig. 2 Per cent Occurrence of Fungi in rhizosphere ofEH-3 and NRS.

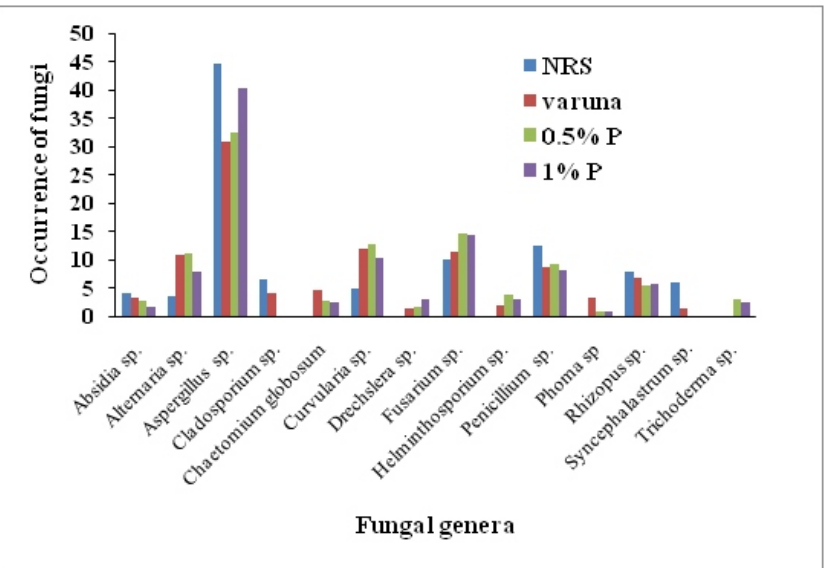

Fig.3 Per cent occurrence of rhizosphere fungi in varuna and NRS.

diversity was there in rhizosphere soil as compared to NRS (Fig. 4). Even maximum rhizosphere effect was observed during the flowering stage as compared to the seedling and maturity stage of the control and treated plants. The rhizosphere effect was higher in plants which were given

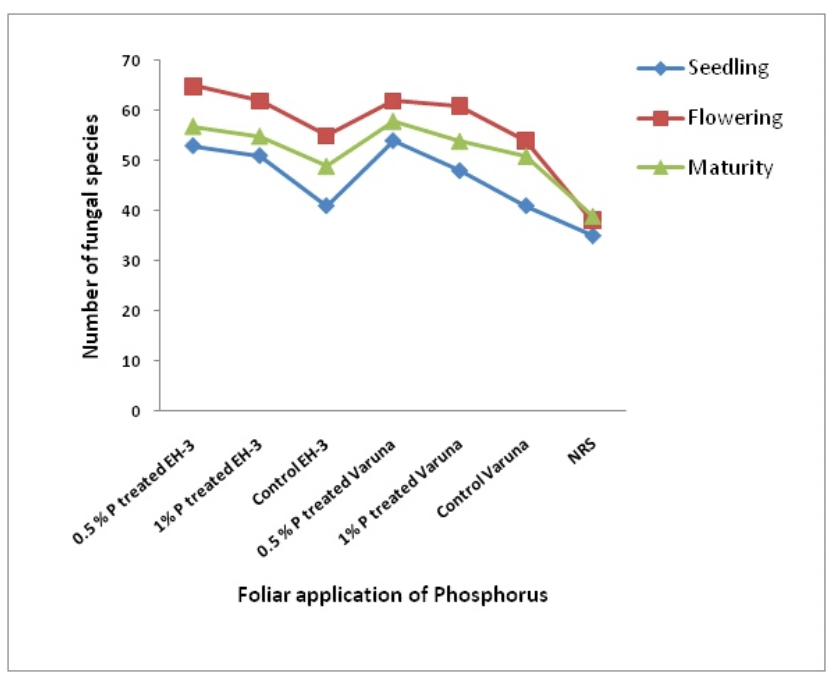

Fig. 4 Rhizosphere mycoflora found in different growth stages of EH-3 and variety varuna. 
Table 2: Rhizosphere effect at different stages of plant growth in control and treated plants

\begin{tabular}{|c|l|c|c|c|c|c|c|c|}
\hline Sr. & Foliar & Concentration & \multicolumn{3}{|c|}{ Cultivar EH-3 } & \multicolumn{3}{|c|}{ Variety varuna } \\
\cline { 4 - 9 } No. & Treatments & (in \%) & S & F & M & S & F & M \\
\hline 1 & Phosphorus & 0.5 & 1.51 & 1.70 & 1.47 & 1.53 & 1.63 & 1.50 \\
& & & $( \pm 0.03)$ & $( \pm 0.08)$ & $( \pm 0.05)$ & $( \pm 0.09)$ & $( \pm 0.11)$ & $( \pm 0.07)$ \\
\hline 2 & Phosphorus & 1 & 1.45 & 1.63 & 1.43 & 1.36 & 1.60 & 1.40 \\
& & & $( \pm 0.06)$ & $( \pm 0.04)$ & $( \pm 0.09)$ & $( \pm 0.05)$ & $( \pm 0.07)$ & $( \pm 0.08)$ \\
\hline 3 & Control & - & 1.17 & 1.43 & 1.26 & 1.17 & 1.42 & 1.33 \\
& & & $( \pm 0.05)$ & $( \pm 0.10)$ & $( \pm 0.04)$ & $( \pm 0.06)$ & $( \pm 0.06)$ & $( \pm 0.05)$ \\
\hline
\end{tabular}

$0.5 \% \mathrm{P}$ treatment as compared to control as well as those given $1 \% \mathrm{P}$ treatment (Table 2).

Rhizoplane fungi: Total 11 genera were isolated from the rhizoplane of treated and control plants of cultivar EH-3 and variety varuna. Per cent occurrence of Aspergillus spp. was most common in comparison to all other fungi isolated. Alternaria sp. Curvularia sp. and Fusarium sp. were also quite common amongst the rhizoplane mycota. However, the important point to be noted is that Penicillum spp., which was prominently present amongst the rhizospheric fungi, was found to be altogether absent in the rhizoplane during the study. There were other fungi also which were present but in very less proportion in comparison. However, there are few fungi which were absent in control but observed in phosphorus treated plants. These are Absidia sp., Helminthosporium sp., Phoma sp., Trichoderma sp. (Table 3).

\section{DISCUSSION}

The results obtained at different stages of plant growth clearly indicate that the rhizospheric fungal diversity is quite rich in microbial population in comparison to nonrhizospheric fungal diversity. Nagaraju and Manoharachary (2017) reported quite a good number of fungal species in NRS and rhizosphere soil. While investigating the rhizosphere and rhizoplane of Brassica juncea for microbial population Tagade and Thakre (2013) stated that the rhizosphere is quite rich in fungal diversity in comparison to the non-rhizosphere soil. Likewise, Bhattacharya and Bora (1995) also reported the highest fungal population in the rhizosphere as compared to nonrhizosphere soil. The reason for this could be the root exudates secreted by the plants which attract greater number of microorganisms towards roots and regulate the soil fungal community and diversity (Broeckling et.al., 2008)

The highest number of colonies of different fungi in both the presently investigated taxa were found at flowering stage. It clearly indicates that flowering is the perfect stage when highest number of fungi get attracted towards the plant root. This observation is in conformity with Deb and Bora (2004), who revealed that the rhizosphere fungal population of leguminous crops like Arachis hypogea and Vigna radiata is more at flowering stage. Presently Aspergillus species were observed as the most dominant fungal microbes both in the rhizosphere of control and foliar treated plants of cultivar EH-3 and variety varuna as has been observed presently. Wakelin et. al., (2004) also stated that Aspergillus spp. along with Penicillium are the dominant P-solubilizing filamentous fungi found in the rhizosphere. However, during the present study of the rhizoplane of cultivar EH-3
Table 3: Total percent occurrence rhizoplane mycota of Brassica juncea in control and phosphorus treated plants.

\begin{tabular}{|c|l|c|c|c|c|c|c|}
\hline \multirow{2}{*}{$\begin{array}{c}\text { S. } \\
\text { No. }\end{array}$} & \multirow{2}{*}{ Fungal isolates } & \multicolumn{2}{|c|}{ Control } & \multicolumn{2}{c|}{ Cultivar $\mathbf{E H - 3}$} & \multicolumn{2}{c|}{ Varety varuna } \\
\cline { 3 - 8 } & & $\mathbf{E H - 3}$ & varuna & $\mathbf{0 . 5 \%} \mathbf{P}$ & $\mathbf{1 \%} \mathbf{P}$ & $\mathbf{0 . 5 \%} \mathbf{P}$ & $\mathbf{1 \%} \mathbf{P}$ \\
\hline 1 & Absidia sp. & 0.0 & 0.0 & 5.1 & 0.0 & 2.6 & 3.4 \\
\hline 2 & Alternaria sp. & 7.9 & 13.7 & 13.2 & 10.8 & 20.7 & 17.6 \\
\hline 3 & Aspergillus spp. & 45.1 & 32.8 & 29.9 & 26.2 & 23.7 & 34.6 \\
\hline 4 & Curvularia spp. & 22.8 & 20.7 & 9.5 & 12.3 & 17.4 & 11.5 \\
\hline 5 & Drechslera sp. & 0.0 & 2.2 & 0.0 & 4.7 & 2.7 & 3.7 \\
\hline 6 & Fusarium spp. & 17.8 & 21.0 & 22.9 & 17.5 & 13.0 & 12.2 \\
\hline 7 & Helminthosporium sp. & 0.0 & 0.0 & 4.7 & 7.9 & 4.6 & 3.7 \\
\hline 8 & Phoma sp. & 0.0 & 0.0 & 1.9 & 3.8 & 1.3 & 1.9 \\
\hline 9 & Rhizopus sp. & 6.3 & 8.6 & 9.1 & 8.4 & 8.1 & 10.3 \\
\hline 10 & Trichoderma viride & 0.0 & 0.0 & 3.1 & 3.0 & 6.1 & 1.2 \\
\hline 11 & Mycelia sterilia & 0.0 & 1.1 & 0.7 & 5.3 & 0.0 & 0.0 \\
\hline
\end{tabular}

and variety varuna Penicillium species was documented. Wahid et.al., (1997) also reported the highest number of Aspergillus and Penicillium species in the rhizoplane of Tomato. Wadhwani and Mehrotra (1982) also reported the specific fungi in rhizosphere and rhizoplane of smut infected plants of Cynodon dactylon.

Siddiqui et. al., (2008) studied the cumulative effect of soil and foliar application of nitrogen, phosphorus and sulfur on rapeseed-mustard genotypes and stated that it enhances parameters like yield, fatty acid composition, etc. They further emphasized that ready supply of the required nutrients to the leaves (site of their metabolism) would more than compensate for the 'hidden hunger' of the growing crop for $\mathrm{N}$ and P. Likewise foliar application of phosphorus during the present investigations might have significantly affected the rhizospheric and rhizoplane fungal diversity and resulted in more fungal population in comparison to control plants.

Most of the fungi isolated from rhizosphere and rhizoplane are largely the same. Fungi like Absidia sp., Alternaria spp., Aspergillus spp., Curvularia spp., Drechslera sp., Fusarium spp., Helminthosporium sp., Phoma sp., Rhizopus sp., and Trichoderma viride are found to be present in both rhizosphere and rhizoplane of Brassica juncea of cultivar line EH-3 and variety varuna. To increase the availability of phosphorus, plant roots have developed a range of mechanisms. Amongst these, organic acids like citrate are reported to be released by roots and proteoid roots to solubalise ions such as phosphate and iron (Jones and Darrah, 1994; Jones et al., 1996). It is a well-established fact that plants absorb $\mathrm{P}$ from the soil in the form of soluble orthophosphate anions $\left(\mathrm{Pi}, \mathrm{H}_{2} \mathrm{PO}_{4}-\right.$ or $\left.\mathrm{HPO}_{4-2}\right)$, which are not readily available in the soil (Goldstein, 1987) and soil microflora play an important role in the release of such non available nutrients into the soil solution from where these are absorbed by the plant roots along with sap.

\section{CONCLUSION}

Foliar application of phosphorus significantly changes the rhizosphere and rhizoplane fungal diversity. The study throws light on the diversity of fungi present in the rhizosphere and rhizoplane of Brassica juncea cultivar line EH-3 and varuna variety and the associated positive effect. The foliar spray of 0.5 and $1 \% \mathrm{P}$ increased the diversity and per cent occurrence of fungal microbes in the rhizospheric and rhizoplane region of the plants used for experimentation. The effect of such 
microbes on plant growth parameters like root length, shoot length, plant height, etc. needs further investigation.

\section{ACKNOWLEDGMENTS}

Authors are thankful to Head, Department of Botany, Rashtrashant Tukadoji Maharaj Nagpur University, Nagpur; DOFCO (Dhara Vegetable Oil and Foods Company Ltd.) for sponsoring the project, Department of Botany, R.T.M. Nagpur University, Nagpur, Maharashtra, India for providing laboratory and financial facilities.

\section{REFERENCES}

Bhattacharya, M. and Bora, K. 1995. Rhizosphere microflora of tea in relation to age of the plants. Indian J. Mycol. Pl. Pathol. 25(3): 263-265.

Booth, C. 1977. The genus Fusarium. CMI, Kew, Surrey, England, 1-237.

Broeckling, C.D. et al., 2008. Root exudates regulate soil fungal community composition and diversity. Applied and environmental microbiology 738-744.

Deb, B. and Bora, K. 2004. Influence of rhizosphere mycopopulation on root nodule formation in leguminous crop. J. Mycol. Pl. Pathol. 34(2): 628630.

Dhedhi, B.M., Gupta, O. and Patel, V.A. 1990. Association of microorganisms in rhizosphere and rhizoplane of healthy and wilted chickpea plants. Indian J. Mycol. Pl. Pathol. 22(1): 72-73.

Goldstein, A.H. 1987. Phosphate starvation inducible excretion of acid phosphatase by cells of Lycopersicon esculentum in suspension culture. $J$. Cell. Biochem. 11(B): 38-42.

Hameeda, B. et al., 2008. Growth Promotion of maize by phosphate solubilizing bacteria isolated from compost and macrofauna. Microbiological research. 163(2): 234-242.

Harley, J.L. and Waid, J.S. 1955.A method of studying active mycelia on living roots and other surfaces in the soil. Trans. Br. Mycol. Soc. 38: 104-118.

Jha, P. K. and Jalali, B. L. 2006. Biocontrol of pea root rot incited by Fusarium solani f. sp. pisi with rhizosphere mycota. Indian Phytopath. 59(1): 41-43.

Johnson, L.F. and Curl, E.A. 1972. Methods for research on the ecology of soil-borne pathogens, Burgess Publishing Company. Pp.7-15.

Jones, D.L., Darrah, P.R. and Kochian, L.V. 1996. Critical evaluation of organic acid mediated dissolution in the rhizosphere and its potential role in root iron uptake. Plant Soil 180: 57-66.

Jones, D.L. and Darrah, P.R. 1994. Role of root derived organic acids in the mobilization of nutrients from the rhizosphere. Plant Soil 166: 247-257.

Kafle, A. et al., 2019. Harnessing soil microbes to improve plant phosphate efficiency in cropping systems. Agronomy 9(127): 1-15.

Katznelson, H. 1946. The rhizosphere effect of mangels on certain groups of soil microorganisms. Soil Sci. 62: 343-354.

Liljeroth, E. and Baath, E. 1988. Bacteria and fungi on roots of different barley varieties (Hordeum vulgare L). Biol. Fert. Soil. 7: 53-57.

Nagaraju, D. and Manoharachary, C. 2017. Fungi associated with non-rhizosphere soil, rhizosphere soil and rhizoplane of Vitex negundo from Telangana. Kavaka 49: 59-64.

Nagmani, A., Kunwar, I.K. and Manoharachary, C. 2006. Hand book of Soil fungi, I. K., International Private limited. 1-496pp.

Raaijmakers, J.M., Paulitz, T.C., Steinberg, C., Alabouvette, C. and Moënne-Loccoz, Y. 2009. The rhizosphere: a playground and battlefield for soilborne pathogens and beneficial microorganisms. Plant Soil 321: 341-36.

Raper, K.B. and Fennell, D.I. 1965. The genus Aspergillus. The Williams and Wilkins Company, Baltimore 1686pp.

Raper, K.B. and Thom, C. 1949. A manual of the Penicillia. Williams \& Wilkins Company, Baltimore 1-875pp.

Seadh, S.E. et al. 2009. Influence of micronutrient foliar application and nitrogen fertilization on wheat yield and quality of grain and seed. J. Biol. Sci. 9: 851858.

Siddiqui, M. H. et al., 2008. Cumulative effect of soil and foliar application of nitrogen, phosphorus, and sulphur on growth, physic-biochemical parameters, yield attributes, and fatty acid composition in oil of erucic acid-free rapeseed-Mustard genotypes. Journal of plant nutrition 31:1284-1298.

Tagade, W.Y. and Thakre, R.P. 2013. Rhizosphere and rhizoplane mycota of Brassica juncea $\mathrm{cv}$ varuna and EH-3. Journal of plant disease sciences 8(1): 92-95.

Wadhwani, K. and Mehrotra, N. 1982. Fungi associated with roots of smut infected plants of Cynodon dactylon. Indian Phytopath. 35: 722 - 724.

Wahid, O.A.A., Moushtafa, A.F. and Ibrahim, M.E. 1997.Soil mycota in tomato fields. Mycoscience 38: 237-241.

Wakelin, S.A. et al. 2004. Phosphate solubilization by Penicillium spp. closely associated with wheat roots. Biol. Fertil. Soils. 40: 36-43. 